\title{
MATRIX RICHARD INEQUALITY VIA THE GEOMETRIC MEAN
}

\author{
MASAYUKi FuJimoto AND YUKi SEO
}

Abstract. In this paper, we show the matrix version of Richard inequality by virture of CauchySchwartz type inequalities via the matrix geometric mean. As an application, we show a matrix Buzano inequality.

Mathematics subject classification (2010): Primary 15A45, secondary 47A64. inequality.

Keywords and phrases: Buzano inequality, matrix geometric mean, Richard inequality, Cauchy-Schwarz

\section{REFERENCES}

[1] M. L. Buzano, Generalizzazione della diseguaglianza di Cauchy-Schwarz, Italian, Rend. Sem. Mat. Univ. c Politcch. Torino 31 (1971/73), 405-409 (1974).

[2] S. S. DRAGOMIR, Refeinements of Buzano's and Kurepa's inequalities in inner product spaces, Facta Universitatis (NIŠ), Ser, Math. Inform., 20 (2005), 65-73.

[3] J. I. FUJII, Operator-valued inner product and operator inequalities, Banach J. Math. Anal., 2 (2008), $59-67$.

[4] M. FujiI AND F. Kubo, Buzano's inequality and bounds for roots of algebraic equations, Proc. Amer. Math. Soc., 117 (2) (1993), 359-361.

[5] M. Fujimoto And Y. Seo, Matrix Wielandt inequality via the matrix geometric mean, Linear Multilinear Algebra (to appear).

[6] F. Kubo And T. Ando, Means of positive linear operators, Math. Ann., 246 (1980), 205-224.

[7] U. Richard, Sur des inégalités du type Wirtinger et application aux équations différentielles ordinaires, Collquium of Analysis held in Rio de Janeiro, August, (1972), 233-244.

[8] F. Zhang, Matrix Theory. Basic results and techniques, Universitext, Springer-Verlag, New York, 1999. 